\title{
Thermal Characterization and Crystallinity Changes in Semicrystalline Poly(ether ester) on UV Irradiations ${ }^{\dagger}$
}

\author{
R. MANI and R. P. SINGH \\ Division of Polymer Chemistry, National Chemical Laboratory, \\ Pune-411 008, India
}

(Received October 14, 1992)

\begin{abstract}
The thermal properties of a segmented poly(ether ester) [Hytrel] were investigated by thermogravimetry and differential scanning calorimetry (DSC). In particular, the influence of irradiation and thermal treatment on the transition temperature and crystallinity of the polymer was studied. DSC and X-ray diffraction were used to assess the crystallinity of poly(ether ester). Crystallinity increases with length of irradiation. However, it was found to decrease with thermal treatment.
\end{abstract}

KEY WORDS Poly(ether ester)/ Thermogravimetry / Differential Scanning

Calorimetry / Polychromatic Irradiation / Thermal Treatment / Crystallinity

/ X-Ray Diffraction /

Segmented thermoplastic poly(ether ester) are of interest as thermoprocessable high performance elastomers offering an unusual combination of physical and chemical properties. $^{1,2}$ These are based on a two-phase structure of "hard" and "soft" block segments in which the latter imparts are elastomeric character to the copolymer. The soft segment is an amorphous segment with low $T_{\mathrm{g}}$. The excellent performance of these elastomeric block copolymers ${ }^{3}$ has stimulated considerable research toward an understanding of their structure-property relationship.

The object of this study was to determine the additive effect of polychromatic irradiation and thermal treatment on a commercially available poly(ether ester), namely, (Hytrel, a trade name of du Pont). Changes in crystallinity were studied by differential scanning calorimetry and X-ray diffraction techniques.

\section{EXPERIMENTAL}

\section{Material}

The material in the study was a commercial sample (Hytrel) received from E. I. du Pont de Nemours \& Co., U.S.A. It is a thermoplastic polyester elastomer and composed of poly(tetramethylene terephthalate) as a "hard" segment and poly(tetramethylene oxy)terephthalate as a "soft" segment. The structure of the resultant copolymer is:

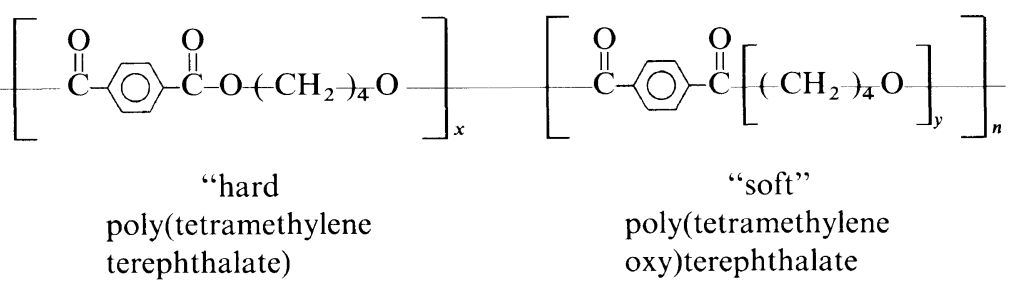

Structure of a typical poly(ether ester)

\footnotetext{
$\dagger^{+}$N.C.L. Communication No: 5634.
} 
The distribution of the copolymer blocks is assumed to be random. The hard segments are capable of undergoing crystallization. The sample was dissolved in chloroform and refluxed for $1 \mathrm{~h}$ in nitrogen atmosphere. The solution was precipitated with $n$-hexane as a non-solvent. The precipitated sample was presumed to be free from processing antioxidants and was filtered and dried under vacuum at $60^{\circ} \mathrm{C}$ for one day.

\section{Experimental Procedure}

The films were made by pressing the material between two teflon sheets at $\sim 210^{\circ} \mathrm{C}$ by applying $350 \mathrm{~kg} \mathrm{~cm}^{-2}$ pressure for 45 seconds in a preheated hydraulic press. The film was quench cooled in tap water for $5 \mathrm{~min}$. The films were kept for thermal exposures in a forced air-oven at $100^{\circ} \mathrm{C}$ and $170^{\circ} \mathrm{C}$ for $0.5 \mathrm{~h}$. Photo-irradiation was carried out in an accelerated photoaging polychromatic irradiation chamber connected with an atmospheric air supply, constructed and calibrated in the laboratory. ${ }^{4}$ The films ( $\sim 120 \mu$ m thickness) of the sample were irradiated with a polychromatic light $(>290 \mathrm{~nm})$ for different time intervals $(200 \mathrm{~h}, 400 \mathrm{~h}, 600 \mathrm{~h}, 800 \mathrm{~h}$, and $1000 \mathrm{~h})$ at $55^{\circ} \mathrm{C}$. The intensity of the irradiation was determined by using a potassium ferri-oxalate actinometry ${ }^{5}$ to be $1.662 \times 10^{-8}$ Einstein $\mathrm{Cm}^{-2} \mathrm{~s}^{-1}$.

\section{Characterization}

The ${ }^{1} \mathrm{H}$ NMR spectrum was recorded by a Bruker $200 \mathrm{MHz}$ NMR spectrometer. The ${ }^{1} \mathrm{H}$ NMR spectrum of the sample was obtained in $\mathrm{CDCl}_{3}$ at room temperature. The compositions of hard and soft segments were calculated ${ }^{6}$ to be $85.8 \mathrm{~mol} \%$ and $14.2 \mathrm{~mol} \%$, respectively.

Thermogravimetric analysis (TGA) was carried out in the temperature range of $25^{\circ}$ to $900^{\circ} \mathrm{C}$ using a NETZSCH Thermal Analyzer STA 409 at a heating rate of $10^{\circ} \mathrm{C} \mathrm{min}^{-1}$ in air. Calorimetric measurements were made using a Perkin Elmer DSC-2 instrument in the range $25-250^{\circ} \mathrm{C}$ at $10^{\circ} \mathrm{C} \mathrm{min}^{-1}$ in nitrogen atmosphere. The samples were cooled at the same rate. Wide angle X-ray scattering diffraction (WAXS) was recorded in the range of $2 \theta=5-35^{\circ}$ using a nickel filtered $\mathrm{Cu}-K_{\alpha}$ radiation $(\lambda=0.1542 \mathrm{~nm})$ from a Phillips $\mathrm{PW}$ $1730 \mathrm{X}$-ray generator. The crystalline fraction was evaluated by DSC curves ${ }^{14}$ and WAXS patterns following the conventional Alexander's procedure ${ }^{7}$ based on graphical separation of intensities due to crystalline and amorphous fractions of the material.

\section{RESULTS AND DISCUSSION}

\section{Characterization of the Sample}

Figure 1 shows a TG thermogram of neat Hytrel sample. The weight loss begins at $180^{\circ} \mathrm{C}$ in air and continues up to $396^{\circ} \mathrm{C}$ in the first

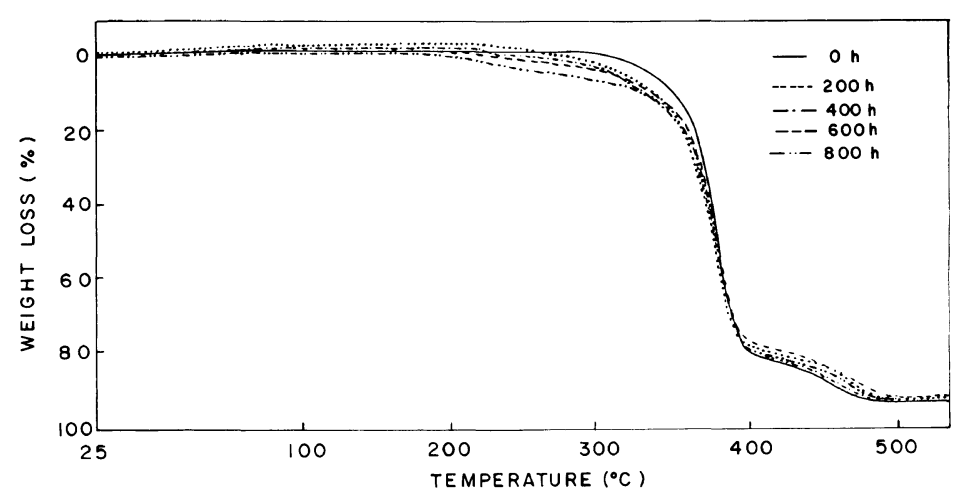

Figure 1. Thermogravimetric analysis of polychromatic irradiated poly(ether ester) films in air. 
Table I. Thermal properties of polychromatic irradiated poly(ether ester)

\begin{tabular}{|c|c|c|c|c|c|c|c|c|c|}
\hline \multirow{2}{*}{$\begin{array}{c}\text { Time of } \\
\text { irradiation } / \mathrm{h}\end{array}$} & \multirow{2}{*}{$\frac{\mathrm{IDT}}{{ }^{\circ} \mathrm{C}}$} & \multirow{2}{*}{$\frac{T_{\max }}{{ }^{\circ} \mathrm{C}}$} & \multirow{2}{*}{$\frac{T_{\mathrm{f}}}{{ }^{\circ} \mathrm{C}}$} & \multirow{2}{*}{$\frac{\text { IPDT }}{{ }^{\circ} \mathrm{C}}$} & \multicolumn{5}{|c|}{ Weight loss } \\
\hline & & & & & $T_{10} /{ }^{\circ} \mathrm{C}$ & $T_{20} /{ }^{\circ} \mathrm{C}$ & $T_{30} /{ }^{\circ} \mathrm{C}$ & $T_{40} /{ }^{\circ} \mathrm{C}$ & $T_{50} /{ }^{\circ} \mathrm{C}$ \\
\hline 0 & 363 & 394.0 & 475.0 & 439.4 & 352 & 368 & 373 & 379 & 384 \\
\hline 200 & 363 & 381.5 & 485.2 & 439.7 & 344 & 360 & 371 & 375 & 377 \\
\hline 400 & 360 & 387.5 & 488.4 & 425.0 & 340 & 361 & 366 & 374 & 377 \\
\hline 600 & 361 & 387.5 & 495.1 & 434.1 & 342 & 364 & 372 & 377 & 380 \\
\hline 800 & 362 & 387.0 & 500.0 & 437.1 & 345 & 366 & 374 & 377 & 382 \\
\hline
\end{tabular}

step and then from $396^{\circ} \mathrm{C}$ to $498^{\circ} \mathrm{C}$ in the second step. The initial decomposition temperature (IDT), maximum decomposition temperature $\left(T_{\max }\right)$, final decomposition temperature $\left(T_{\mathrm{f}}\right), 10 \mathrm{wt} \%$ decomposition temperature $\left(T_{10}\right)$ to $50 \mathrm{wt} \%$ decomposition temperature $\left(T_{50}\right)$ were read off from the TG curves and are given in Table I. Integral procedural decomposition temperature (IPDT) was calculated from normalized curves using the Doyle's equation $^{8}$ :

$$
T^{*}=875 A^{*}+25
$$

where $T^{*}$ represents IPDT and $A^{*}$ is the total area under the normalized TG curves from $25^{\circ} \mathrm{C}$ to $900^{\circ} \mathrm{C}$.

Two peaks were found among various DSC thermograms (Figure 2). The thermogram of $0 \mathrm{~h}$ shows a hard segment melting peak (melting temperature, $T_{\mathrm{m}}=203.4^{\circ} \mathrm{C}$ ) which is in good agreement with the literature. ${ }^{9}$ In addition to $T_{\mathrm{m}}$, another endothermic peak associated with the crystalline phase appeared on the DSC thermograms at $214^{\circ} \mathrm{C}$ and was ascribed to the melting of poorly ordered crystals formed at the processing temperature. ${ }^{10}$ The thermogravimetric and DSC results show that the poly(ether ester) has some unique features. The segmental incompatibility causes microphase separation of amorphous component. The two-phase structure of the polymer in our investigation confirms several workers ${ }^{7,11-13}$ who concluded that crystalline domains serve to fix the amorphous phase material into an elastic network or a more or less continuous

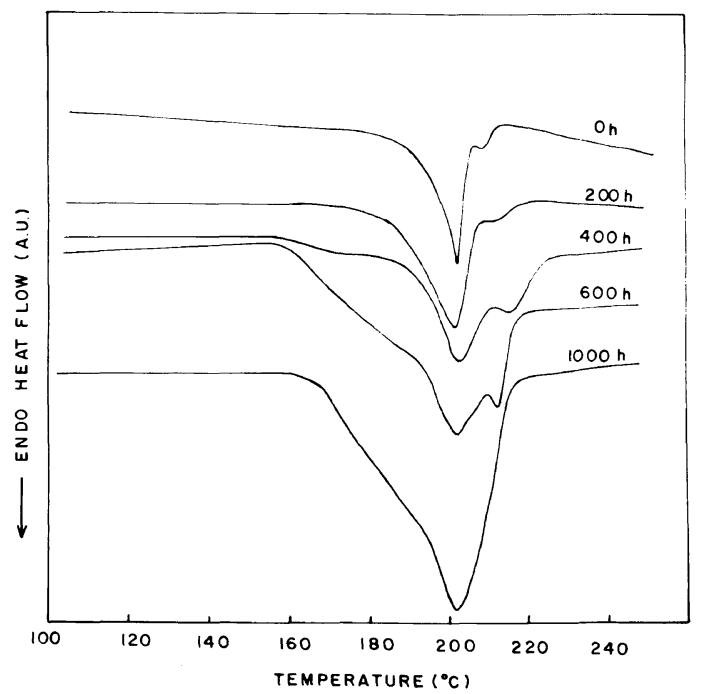

Figure 2. Heating DSC curves for polychromatic irradiated poly(ether ester) films.

crystalline network is superimposed on a continuous network. Figure 3 shows the recrystallization behavior of the polymer upon cooling isothermally from $250^{\circ} \mathrm{C}$ to $60^{\circ} \mathrm{C}$. The crystallization peak $\left(T_{\mathrm{c}}\right)$ was observed at $176.2^{\circ} \mathrm{C}$.

The wide angle X-ray diffractogram of unexposed sample is given Figure 4. Crystalline peaks were observed at scattering angle $2 \theta=17.3^{\circ}, 20.6^{\circ}, 23.4^{\circ}$, and $25.1^{\circ}$. The $h k l$ crystallographic planes corresponding to these angles were estimated as [010], [012], [100], and [103].

\section{Effect of UV Irradiation}

A marginal change in $T_{\max }$ and $T_{\mathrm{f}}$ was 
observed upon irradiation of poly(ether ester) sample (Figure 1), indicating that UV irradiation brought about no appreciable change in the chemical structure of the poly(ether ester). The DSC thermograms show a progressive change (Figure 2) after irradiations for $200 \mathrm{~h}$, $400 \mathrm{~h}, 600 \mathrm{~h}$, and $1000 \mathrm{~h}$. In case of irradiated samples, the first endotherm occurs at lower temperature which suggests that crystallite size slightly decrease upon irradiation but irradiation for prolonged periods eliminates the second endotherm and is replaced by a very broad endotherm. This means that the second endotherm is due to poorly ordered crystals. The melting enthalpy $\left(\Delta H_{\mathrm{m}}\right)$, estimated from

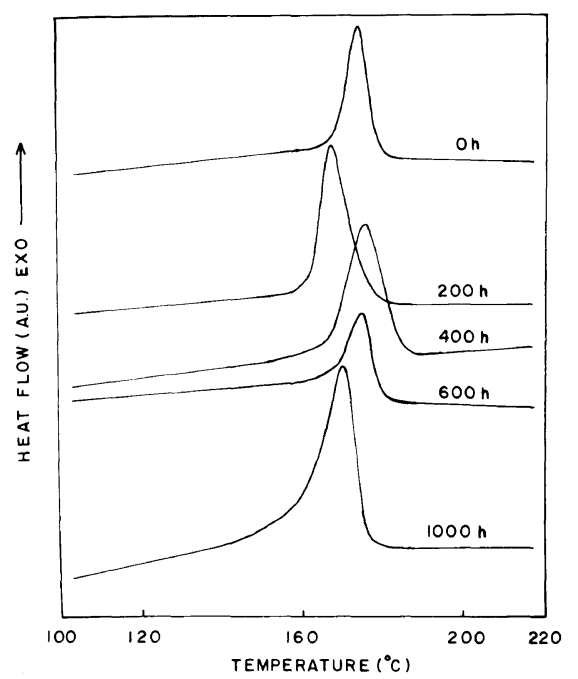

Figure 3. DSC cooling exotherm for polychromatic irradiated poly(ether ester) films. the area of first endotherm, decreases to $200 \mathrm{~h}$ irradiation but increases continuously thereafter. This implies that for lower irradiation periods $(200 \mathrm{~h})$ the presence of a soft segment acts as a diluent for the hard segment but at longer irradiation periods, the increase in $\Delta H_{\mathrm{m}}$ indicates that a soft segment co-crystallizes with a hard segment leading to better alignment in the crystalline lattice. From DSC parameters (Table II) it can be seen that crystallinity $\left(X_{c}\right)$ also increases for prolonged periods of irradiation. Crystallinity increase is due to increasing average crystallizable blocks and is calculated based on the value of $\Delta H_{\mathrm{m}}$ (7.5 $\mathrm{kcal} \mathrm{mol}^{-1}$ ) for $100 \%$ crystalline poly(tetramethylene) terephthalate. ${ }^{14}$

Figure 3 shows variation in crystallization peak $\left(T_{\mathrm{c}}\right)$ and temperature of onset of crystallization ( $T_{\text {onset }}$ ) upon irradiation. $T_{\mathrm{c}}$ and $T_{\text {onset }}$ both shift to lower values with increasing irradiation periods (Table II) indicating that crystallizing ability of a polymer is improved with increasing time of irradiation. The crystallization process is accelerated by lowering $T_{c}$ and $T_{\text {onset }}$. The half width of crystallization exotherm $\left(\Delta T_{\mathrm{c}}\right)$, a measure of crystallization rate, is also found to increase with irradiation. Hence we can say that irradiation facilitates crystallization and increases the rate of crystallization.

The changes in wide angle $\mathrm{X}$-ray diffractograms of thermally treated (at $100^{\circ} \mathrm{C}$ and $170^{\circ} \mathrm{C}$ ) and $\mathrm{UV}$ irradiated samples are shown in Figures 4 and 5. Table III lists the X-ray

Table II. Melting temperature $\left(T_{\mathrm{m}}\right)$, melting enthalpy $\left(\Delta H_{\mathrm{m}}\right)$, percent crystallinity $\left(X_{\mathrm{c}} \%\right)$, crystallization temperature $\left(T_{\mathrm{c}}\right)$, crystallization onset temperature $\left(T_{\text {onset }}\right)$, and half width of crystallization $\left(\Delta T_{\mathrm{c}}\right)$ of poly(ether ester) upon polychromatic irradiation

\begin{tabular}{|c|c|c|c|c|c|c|}
\hline \multirow{2}{*}{$\begin{array}{l}\text { Time of } \\
\text { irradiation } / \mathrm{h}\end{array}$} & $T_{\mathrm{m}}$ & $\Delta H_{\mathrm{m}}$ & $X_{\mathrm{c}}$ & $T_{\mathrm{c}}$ & $T_{\text {onset }}$ & $\Delta T_{\mathrm{c}}$ \\
\hline & ${ }^{\circ} \mathrm{C}$ & $\mathrm{C} \cdot \mathrm{g}^{-1}$ & $\%$ & ${ }^{\circ} \mathrm{C}$ & ${ }^{\circ} \mathrm{C}$ & ${ }^{\circ} \mathrm{C}$ \\
\hline 0 & 203.4 & 7.02 & 20.53 & 176.2 & 184.1 & 5.46 \\
\hline 200 & 201.7 & 6.32 & 18.48 & 167.3 & 175.2 & 7.73 \\
\hline 400 & 202.6 & 6.91 & 20.21 & 175.8 & 183.7 & 9.27 \\
\hline 600 & 203.0 & 9.98 & 26.67 & 174.8 & 179.3 & 9.36 \\
\hline 1000 & 201.4 & 18.23 & 53.30 & 169.9 & 175.1 & 9.82 \\
\hline
\end{tabular}


crystallinity of the WAXS diffractograms. Thermal exposure and polychromatic irradiation significantly changes the $\mathrm{X}$-ray diffraction patterns. Thermal treatment for short duration $(0.5 \mathrm{~h})$ decreases crystallinity where fragmentation predominates with increasing temperature but upon irradiation and increase in $X_{\mathrm{c}}$ was observed which is seen from the peak intensity

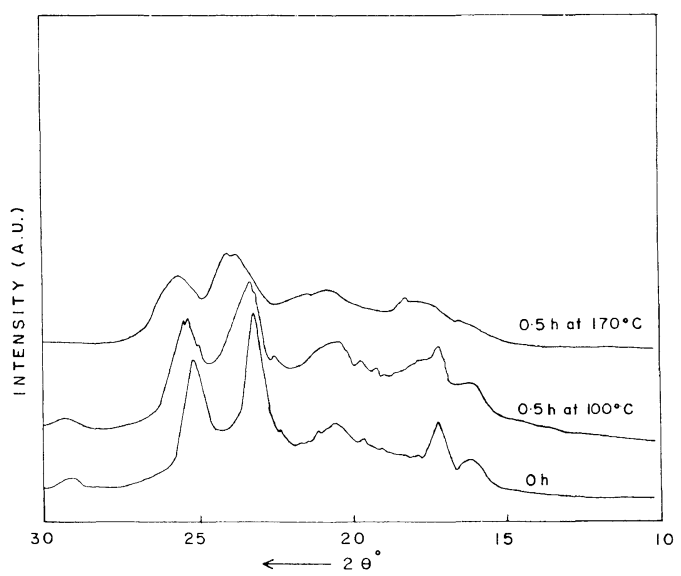

Figure 4. Variation of X-ray diffraction pattern of thermal treated poly(ether ester) films. also. The increase in crystallinity may be due to order in the crystal lattice which causes 'regularity' in the polymer chain upon irradiation.

We therefore conclude that crystallinity of poly(ether ester) depends upon preceeding thermal treatment/polychromatic irradiation of the specimen. Irradiation improves compatibility between the phases and hence the dispersion of soft segment domains in poly-

Table III. Variation in percent crystallinity $\left(X_{\mathrm{c}} \%\right)$ of thermally exposed and polychromatic irradiated poly(ether ester)

\begin{tabular}{lc}
\multicolumn{1}{c}{ Time of irradiation } & $X_{\mathrm{c}}$ \\
Thermal and photo & $\%$ \\
\hline $0.0 \mathrm{~h}$ & 36.4 \\
Heated at $100^{\circ} \mathrm{C}$ for $0.5 \mathrm{~h}$ & 35.5 \\
Heated at $170^{\circ} \mathrm{C}$ for $0.5 \mathrm{~h}$ & 25.1 \\
Irradiated at $55^{\circ} \mathrm{C}$ for $200 \mathrm{~h}$ & 44.3 \\
Irradiated at $55^{\circ} \mathrm{C}$ for $400 \mathrm{~h}$ & 40.4 \\
Irradiated at $55^{\circ} \mathrm{C}$ for $600 \mathrm{~h}$ & 51.5 \\
Irradiated at $55^{\circ} \mathrm{C}$ for $800 \mathrm{~h}$ & 52.1 \\
Irradiated at $55^{\circ} \mathrm{C}$ for $1000 \mathrm{~h}$ & 43.4
\end{tabular}

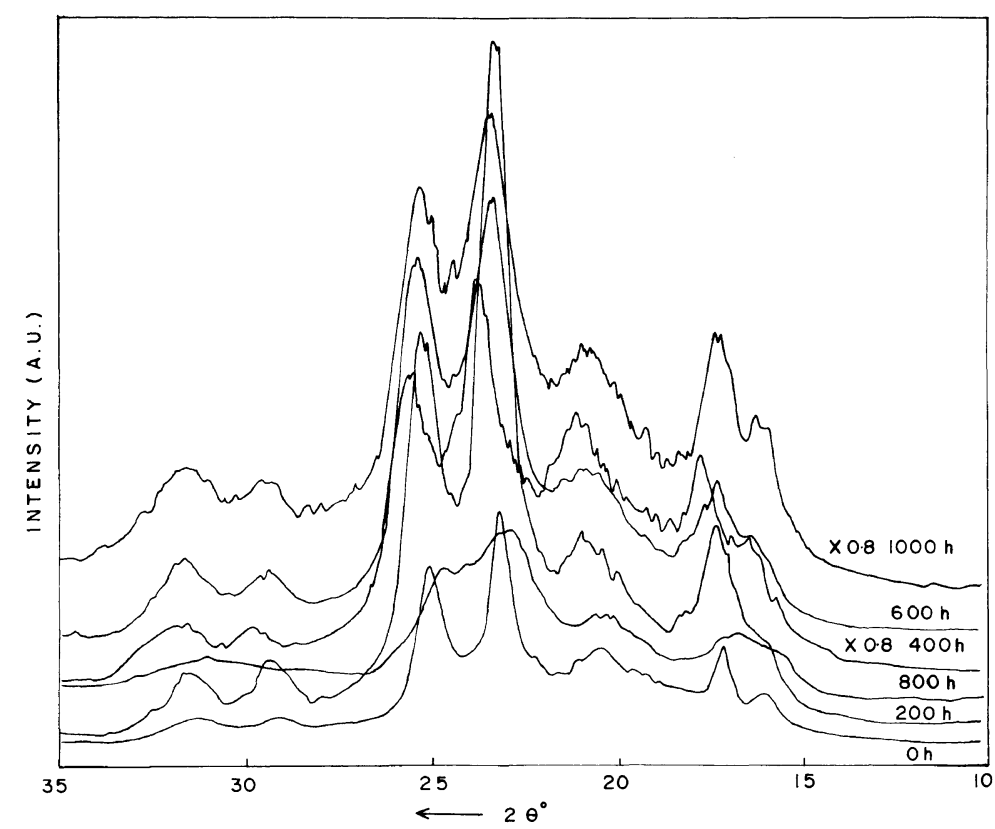

Figure 5. Variation of X-ray diffraction pattern of polychromatic irradiated poly(ether ester) films. 
(tetramethylene terephthalate) matrix. On prolonged irradiation, a soft segment acts as a compatibilizer for a hard segment and ‘selectively extracts steric defects leaving a matrix of hard segment which causes higher crystallinity. Irradiation slightly increases compatibility and crystallinity due to reorganization of crystallizable units into lamella.

Acknowledgements. The authors thank the Indo-French Center for Promotion of Advanced Research (Centre Franco-Indian Pour la Promotion de la Researche Avance) for financial support through Grant No. 308-6 and Dr. S. Sivaram, Deputy Director and Head, Polymer Chemistry Division, National Chemical Laboratory, Pune, India for his encouragement and suggestions during this study. RM is greatful to CSIR (India) for the award of a junior research fellowship.

\section{REFERENCES}

1. J. C. Shivers, U.S. Patent 3,023,192 (1962).

2. A. A, Nishimura and H. Komagata, J. Macromol. Sci., A1, 619 (1967).

3. H. Kobayashi, Japapense Patent Appl. 44-20469 (1969).

4. R. P. Singh and A. Singh, J. Macromol. Sci.-Chem., A28, 487 (1991).

5. J. G. Calvert and N. J. Pitts, Jr., "Photochemistry," John Wiley \& Sons, New York, N.Y., 1966, Chapter 7, p 785.

6. G. Perego, M. Cesari, and G. D. Fortura, J. Appl. Polym. Sci., 29, 1141 (1984).

7. L. E. Alexander, "X-Ray Diffraction in Polymer Science," Wiley Interscience, New York, N.Y., 1969, Chapter 3, p 165.

8. C. D. Doyle, Anal. Chem., 33, 77 (1961).

9. Encycl. Polym. Sci. Technol., 11, 69 (1977).

10. S. Y. Hobbs and C. F. Pratt, Polymer, 16, 462 (1975).

11. R. J. Cella, Encycl. Polym. Sci. \& Technol., Suppl., 2, 485 (1977).

12. D. J. Hourston and I. D. Hughes, J. Appl. Polym. Sci., 21, 3093 (1977).

13. T. Nishi and T. K. Kwei, J. Polym. Sci., 20, 1331 (1976).

14. I. Kirshenbaum, J. Polym. Sci., A, 3, 1869 (1965). 